\title{
DESAFIO PARA A CAPELANIA NO SÉCULO XXI: SUPORTE ESPIRITUAL APÓS CATÁSTROFES NATURAIS
}

\section{ARTIGO ORIGINAL}

CUNHA, David Carvalho ${ }^{1}$

CUNHA, David Carvalho. Desafio para a capelania no século XXI: Suporte espiritual após catástrofes naturais. Revista Científica Multidisciplinar Núcleo do Conhecimento. Ano 04, Ed. 07, Vol. 03, pp. 77-89. Julho de 2019. ISSN: 2448-0959

\section{RESUMO}

O grande número de ocorrências de catástrofes naturais no Brasil, principalmente nas últimas duas décadas, tem se apresentado como um desafio para a capelania diante de pessoas que tiveram perdas de bens materiais e na vida de familiares. Dessa maneira, surge o seguinte questionamento: como falar para alguém que perdeu tudo, de um Deus amoroso, mas que "não impediu" o desastre ou "não as ajudou" durante o momento do ocorrido? O presente estudo tem como objetivo apresentar quatro fundamentos, através de argumentações bíblicas, sobre os quais deverá ser viabilizado um suporte espiritual eficaz pós-catástrofes naturais. Foi realizada pesquisa qualitativa de dados, a partir da pesquisa bibliográfica. $\mathrm{Na}$ conclusiva, destaca-se o amor de Deus como justificativa para o seu modo de agir, e, as bases para uma abordagem assertiva a ser feita pelo capelão visando apresentar ao seu assistido o verdadeiro entendimento em relação ao propósito, a vontade, as permissões e as providências de Deus.

Palavras-Chave: Catástrofes naturais, capelania, Deus, amor.

1 Engenharia com ênfase em eletrônica (CEFET-RJ) ; Seminário teológico interconfessional (Uninter); Pós-graduação em Capelania (Faveni); Pós-graduação em História das Religiões (Faveni). 


\section{INTRODUÇÃO}

Tragédias de todos os tipos e categorias são fatos constantes na história da humanidade e a frequência das ocorrências naturais de magnitudes trágicas aumentou consideravelmente nas últimas décadas trazendo grandes evacuações, desmobilizações em massa, perdas materiais irreparáveis e de vidas humanas. Nesse contexto surge o serviço de capelania pós-catástrofes naturais visando conduzir o capelão ao encontro de pessoas que passaram por tragédias dessa natureza e oferecer assistência religiosa, que compreende a arrecadação de alimentos, de vestimentas, de itens básicos para a reconstrução de um novo lar e suporte espiritual.

Entretanto, mais importante do que reaver bens, propriedades ou riquezas materiais que custam algum preço alcançável, é obter a cura de um trauma, a felicidade emocional e o verdadeiro prazer em conseguir novamente amar algo e alguém sem o medo de perdê-lo, ou seja, é atribuir valor ao que de fato representa relevância. Marcas físicas certamente podem ser resolvidas com o tempo ou com artifícios naturais, porém existem questões que somente Deus fará com que o homem supere e alcance o pleno sentido do viver. E aqui descobrimos a importância da estratégia de Deus quanto ao chamado do capelão nesse contexto, pois até mesmo uma cidade poderia ser reconstruída, mas se os cidadãos não passarem por uma reconstrução interior consequentemente em vão terão trabalhado os edificadores.

Logo, o grande dilema repousa no suposto paradoxo de que Deus teria completa condição de prever e impedir uma tragédia, mas não necessariamente o faz, ou seja, ao mesmo tempo em que ele possui atributos incomunicáveis ao homem, como a onisciência e a onipotência, ele também é amor. Então, como falar, a alguém que perdeu tudo, de um Deus que as ama, mas não impediu o desastre ou não as ajudou no momento de crise? Com isso, quais seriam os argumentos cristãos necessários para que o capelão consiga abordar de forma eficaz alguém que vivenciou tal fato?

Este estudo tem o objetivo de apresentar argumentos bíblicos que possam contribuir para que o capelão desenvolva um suporte espiritual eficaz após uma catástrofe natural. Para isso, em um primeiro momento, definiremos catástrofes naturais, bem 
como as suas causas e consequências, conceituaremos capelania e capelania póscatástrofes e por fim fundamentaremos biblicamente as quatro bases que darão suporte a abordagem do capelão.

O método empregado na pesquisa foi o bibliográfico, utilizando-se de livros e sites eletrônicos como base para obtenção de definições conceituais, coleta de informações e estatísticas, e ainda, foi utilizada a Bíblia Sagrada como fonte para a construção dos princípios necessários para o estabelecimento da abordagem proposta ao capelão, sendo também destacados alguns detalhes da história do personagem chamado Jó, que para o teor dessa pesquisa talvez seja o melhor exemplo de alguém que tenha vivenciado uma catástrofe e conseguido em Deus reconstruir a sua vida.

\section{DESENVOLVIMENTO}

Toda a problemática que envolve uma grande tragédia precisa ser equacionada de forma a possibilitar o estabelecimento da harmonia entre o Deus amoroso e o homem carente. Dessa forma, será apresentada abaixo a relação entre catástrofes naturais, capelania pós-catástrofes e os respectivos princípios bíblicos a serem propostos.

\subsection{CATÁSTROFES NATURAIS}

Castro (1998, p. 52) define catástrofe ou desastre como: "[...] Resultado de eventos adversos, naturais ou provocados pelo homem, materiais e/ou ambientais e consequentes prejuízos econômicos e sociais [...]. E, segundo relatado no site Fatos Desconhecidos as cinco piores catástrofes ocorridas neste século, totalizando aproximadamente 450.000 mortos, foram o tsunami na Indonésia em 2004, o furacão Katrina nos Estados Unidos em 2005, o terremoto de Caxemira em 2005, o terremoto do Haiti em 2010 e o tufão nas Filipinas em 2013 ${ }^{[2]}$. Exemplos ainda mais atuais ocorridos em 2019 no Brasil, são informados no site Exame onde se destacam o rompimento da barragem de Brumadinho-MG em 25/01/2019, a tempestade na cidade do Rio de Janeiro-RJ em 06/02/2019 e o desabamento de terra na cidade de MauáSP em 16/02/2019[3]. 
Segundo a Organização Mundial das Nações Unidas para a Educação, a Ciência e a Cultura (Editora UNESCO, 2015), alguns dos riscos mais comuns classificados como causadores de desastres naturais são os meteorológicos (furacões, tornados, ondas de calor, raios e incêndios), hidrológicos (inundações súbitas ou enxurradas e tsunamis), geológicos (vulcões, terremotos, movimentos de massa como quedas, deslizamentos, depressões), astrofísicos (meteoritos), biológicos (epidemias e pragas), e, antrópicos (conflitos armados, incêndios, poluição, falta de infraestrutura ou colapso, confrontos sociais e terrorismo). E, ainda, muitos desastres naturais são originados devido a ações humanas imprudentes [...], destacando que o número de ocorrências de desastres naturais aumentou em aproximadamente cinco vezes desde os anos de $1970^{[4]}$, e, ainda, cerca de 4 bilhões de pessoas nas últimas duas décadas precisaram de algum tipo de assistência humanitária pois encontravam-se desalojadas e desabrigadas, feridas ou em situação de emergência, onde mais de 1,35 milhões de pessoas perderam a vida nos últimos 20 anos ${ }^{[5]}$.

Os fatos expostos acima revelam a relação diretamente proporcional que existe entre as ações humanas realizadas na natureza e o crescente aumento em ocorrências de catástrofes naturais. Essas intervenções do homem visam o desenvolvimento tecnológico em todas as áreas através da construção de indústrias e barragens, a confecção de automóveis e aviões, a exploração de recursos naturais, etc., porém, a consequência desastrosa dessas ações é a exposição da sociedade aos riscos meteorológicos, hidrológicos, geológicos, biológicos, antrópicos, etc.

Conforme descrito na Bíblia (1993, Jó, 1 e 2), Jó morava em Uz, região da Mesopotâmia, possuía uma família estruturada, muitos animais, sendo o homem mais rico do oriente e destacado pelo próprio Deus como integro, reto, temente e que se desvia do mal. Porém, sobreveio sobre ele, sobre seus 10 filhos e seus muitos animais catástrofes múltiplas (biológicas, antrópicas e meteorológicas), fazendo com que Jó perdesse todos os seus bens, todos os seus filhos e a sua saúde [...]. Cabe aqui ressaltar nesse contexto catastrófico uma importante declaração a respeito de Jó: "em tudo isso Jó não pecou, nem atribuiu a Deus falta alguma." (BÍBLIA, Jó, 1:22) 


\subsection{CAPELANIA}

A capelania representa uma grande estratégia divina quanto a atuação e o alcance de vidas em todos os aspectos e ambientes da sociedade. Alves (2017, pg 234) concorda afirmando que a área de atuação do capelão extrapola as quatro paredes da igreja levando-o ao encontro do assistido, dessa forma, possibilitando o alcance de pessoas que não estarão no ambiente congregacional da igreja [...]. Essa saída estratégica realizada pelo capelão de forma não convencional, visa levar as verdades das Escrituras Sagradas e o conforto de Deus seguindo o caminho "a igreja indo ao homem" e não "o homem indo à igreja". Sendo garantida a assistência religiosa em instituições públicas e privadas, e o alcance de pacientes em hospitais, internos em presídios e militares, conforme o Art. $1^{\circ}$ da Lei $n^{\circ}$ 9.982, de 14 de julho de 2000 (BRASIL, 2000).

Com o objetivo de aperfeiçoar a atuação junto às mais variadas necessidades a capelania dividiu-se entre as diversas áreas da sociedade. Nesse contexto surge a capelania pós-catástrofes atuando na assistência religiosa de forma particular ou junto a órgãos públicos, empresas privadas, ONG, etc. Um exemplo prático do interesse da capelania em se aprimorar diante da necessidade observada no contexto póscatástrofe pode ser representado pelo Serviço Nacional de Capelania Pós-Desastres (SENCAP), criado através de uma associação cristã sem fins lucrativos, tendo por objetivo orientar, capacitar e treinar voluntários para a atuação em prevenções, preparação de emergências e resposta aos desastres em nosso território[6].

Ainda que não diretamente formalizado como uma assistência religiosa, a Bíblia (1993, Jó, 4 à 26) mostra que Jó recebeu a visita de quatro homens, três deles classificados como sendo seus amigos. E, esses três amigos passam a dialogar com Jó buscando interpretar os porquês da tragédia ocorrida e orientá-lo quanto aos possíveis meios para a sua solução e restauração [...]. 


\subsection{FUNDAMENTAÇÃO BÍBLICA}

Quando nos encontramos diante de situações extremamente críticas que envolvem perdas irreparáveis e emoções quase que incontroláveis, muito provavelmente, chegaremos à conclusão de que nesses momentos as palavras humanas se tornarão indiferentes, falhas e incapazes de minimizar toda a dor sentida. Isso porque representam tentativas humanas de consolo. Contudo, o apóstolo Paulo ensina que: "[...] o Deus de toda consolação, nos consola em todas as nossas tribulações, para que também sejamos capazes de consolar os que passam por qualquer tribulação [...]" (BÍBLIA, 2 Coríntios, 1:4), e, o salmista declara: "enviou-lhes a sua palavra, e os sarou, e os livrou das suas tribulações" (BÍBLIA, Salmos, 107:20, grifo nosso), logo, temos a convicção de que existem pessoas preparadas por Deus para levar o consolo, a cura e o livramento sobre toda e qualquer tribulação através da palavra de Deus. Por isso, a Bíblia constitui-se como o instrumento suficiente para que o capelão consiga transformar a tentativa de explicação e de conforto no sucesso da explanação da verdade e da aplicação do consolo em meio ao caos. Somente através da Bíblia o ser humano poderá entender o porquê Deus permite situações e como ele providencia fatos para a realização do seu propósito e da sua vontade. A Bíblia (1993, Jó, 40:3 à 5) revela que Jó respondia as proposições dos seus amigos, porém quando Deus começou a falar, ou seja, quando a palavra de Deus passou a ser ouvida, Jó reconheceu sua insignificância e se calou para somente ouvir e entender [...].

Com isso, faz-se necessário destacar o amor de Deus como sendo o elemento suficiente que garante a preservação do seu propósito e a imutabilidade da sua vontade para a criação, proporcionando permissões estratégicas e providências restauradoras na história da humanidade. Então, desenvolveremos esses quatro princípios como subsídio para a realização de uma abordagem consciente que visa o esclarecimento e a transformação de vidas.

O apóstolo João anuncia o resultado de tão grande amor: "Porque Deus amou ao mundo de tal maneira que deu o seu Filho unigênito, para que todo o que nele crê não pereça, mas tenha a vida eterna." (BÍBLIA, João, 3:16), e ainda: "[...] pois Deus é amor." (BÍBLIA, 1 João, 4:8) 


\subsubsection{O PROPÓSITO DE DEUS PARA A CRIAÇÃO ANTES DO PECADO}

Deus é o motivo único da existência do universo e o supremo poder da sua palavra é suficiente para tornar real a sua vontade. O escritor bíblico da carta aos Hebreus diz que "Pela fé, entendemos que foi o universo formado pela palavra de Deus, de maneira que o visível veio a existir das coisas que não aparecem." (BÍBLIA, Hebreus, 11:3, grifo nosso). Em conformidade, o escritor de Gênesis nos apresenta a aprovação do Criador após concluir a sua criação: "Viu Deus tudo quanto fizera, e eis que era muito bom [...]" (BÍBLIA, Gênesis, 1:31). E, ainda, fazendo uma referência profética ao período posterior ao exílio babilônico, o profeta Isaías afirma: "[...] o Deus que formou a terra, que a fez e a estabeleceu; que não a criou para ser um caos, mas para ser habitada [...]" (BÍBLIA, Isaías, 45:18). Logo, sobre esse panorama Deus revela o grande propósito para a criação do universo: a habitação do ser humano. Um propósito graciosamente amoroso foi inteligentemente planejado e cuidadosamente executado, resultando em um ambiente perfeito para a nossa moradia. Como exemplo, sobre essa perspectiva, pode-se destacar o cuidado de Deus para com a vida de Jó fato esse que motivou as palavras do adversário: "Acaso, não o cercaste com sebe, a ele, a sua casa e a tudo quanto tem? A obra de suas mãos abençoaste, e os seus bens se multiplicaram na terra." (BÍBLIA, Jó, 1:10)

Com isso, apresentamos aqui o primeiro ponto a ser considerado pelo capelão para a sua abordagem em um contexto catastrófico: O propósito amoroso do criador em relação a sua criação. Então, nesse primeiro momento o capelão apresentará aos seus assistidos o propósito inicial de Deus para a sua criação.

\subsubsection{A VONTADE DE DEUS PARA A CRIAÇÃO APÓS O PECADO}

A Bíblia (1993, Gênesis, 3), explica que uma vez criado o universo, estabelecidas as condições necessárias para a preservação da vida e formado o homem, aconteceu o problema do pecado na raça humana. A desobediência do casal (Adão e sua mulher) diante da ordem expressa de Deus trouxe consequências desastrosas a todos os 
reinos da criação (mineral, vegetal e animal). Com isso, o poder do pecado aprisionou toda a criação e amaldiçoou a terra fazendo com que fossem produzidos espinhos e ervas daninhas. Então, a morte tornou-se uma dura realidade para a humanidade como resultado direto ao pecado cometido [...]. Diante dessa realidade, uma vez que o homem tenha se colocado em oposição ao cumprimento do propósito original da criação, Deus revela que o seu amor é plenamente capaz de preservar a sua boa, agradável e perfeita vontade. Deus é santo e completamente imune aos nossos atos, sejam eles positivos ou negativos. Ou seja, não existe nada que possamos fazer de bom para que Deus nos ame mais ou de mal para que ele deixe de nos amar. Sendo Deus onisciente, a Bíblia (1993, 1 Pedro, 1:19 e 20) vai revelar que antes de realizar a criação ele deveria decidir nos perdoar e providenciar a nossa salvação, pois já era conhecedor das realidades ainda não acontecidas [...]. Inspirado pelo Espírito Santo o apóstolo Paulo revela que até: "[...] a própria criação será redimida do cativeiro da corrupção, para a liberdade da glória dos filhos de Deus." (BÍBLIA, Romanos, 8:21).

Com isso, apresentamos o segundo ponto a ser considerado pelo capelão para a sua abordagem em um contexto catastrófico: A vontade salvífica do criador diante do pecado da raça humana. Então, nesse segundo momento o capelão explicará durante a sua assistência a realidade do pecado e o plano de salvação de Deus para a humanidade.

\subsubsection{AS PERMISSÕES DE DEUS NA HISTÓRIA DA HUMANIDADE PECADORA}

É perceptível que entre nós seres humanos existe uma falsa sensação de que Deus reagiria de forma positiva ou negativa em correspondência aos nossos atos. E sem dúvida, essa sensação implicaria diretamente na existência de um Deus injusto diante daqueles que se julgam merecedores de receber boas dádivas. Em contrapartida, a Bíblia (1993, Jó, 3:25) esclarece o fato de que coisas boas acontecem com pessoas más e coisas más acontecem com pessoas boas [...]. Como veremos, o exemplo do furacão Patrícia corrobora com essa afirmação. Conforme relatado no site da revista Veja esse foi o maior e mais poderoso fenômeno do tipo já registrado na história, e o 
nome dado a esse fenômeno merece uma atenção maior ainda[7]. A Organização Meteorológica Mundial (OMM), uma agência da Organização das Nações Unidas (ONU), é a responsável por organizar e atualizar a lista dos nomes ${ }^{[8]}$. É curiosa a relação que existe entre a origem das palavras Patrícia, Pátria e Pai[9], ou seja, o nome escolhido para o maior e mais forte furacão da história se relaciona com a palavra pai e isso talvez represente o sentimento mais profundo que o ser humano possui a respeito da causa de uma grande catástrofe: Deus (o Pai) deve ser o único responsável pelo cuidado dos seus filhos (seres humanos). Logo, sobre esse ponto de vista, Deus deveria ser o responsável por criar coisas boas ou por permitir coisas más. Segundo a Bíblia (1993, Jó, 4 à 26), essa teologia da retribuição foi defendida pelos três amigos de Jó, conforme os seus discursos, em uma tentativa de consolo e ajuda $[\ldots]$.

Porém, a grande verdade é que o homem deve ser o responsável por suas escolhas e não atribuir culpa alguma a Deus pelas suas consequências. Ainda que, Deus seja completamente capaz de evitar tragédias, o fato dele não as impedir não o torna culpado. O apóstolo Paulo ensina que: "[...] pois aquilo que o homem semear, isso também ceifará." (BÍBLIA, Gálatas, 6:7). Passar por toda uma vida indiferente a Deus e no final atribuir a ele os acontecimentos ruins seria no mínimo incoerente. O pecado causa separação entre o homem e Deus, e quando Deus decide através da graça abrir o caminho para a reconciliação, isso representa uma atuação em todas as oportunidades possíveis. E, definitivamente existem momentos específicos em que o homem estará mais receptivo ou sensível a perceber, ouvir e entender o propósito e a vontade de Deus. No caso de Jó, esse momento chegou somente após algum tempo de reflexão pós-catástrofe, onde ele declara: "Eu te conhecia só de ouvir, mas agora os meus olhos te veem. Por isso, me abomino e me arrependo no pó e na cinza." (BÍBLIA, Jó, 42:5 e 6).

A Bíblia (1993, Romanos, 1:19 e 20) ensina que a natureza é um dos meios de revelação ao homem sobre o conhecimento a respeito de Deus [...], nesse caso, os maiores e mais trágicos fenômenos físicos da natureza também devem trazer revelação a respeito do criador. A história da libertação dos hebreus da escravidão 
egípcia, descrita pela Bíblia (1993, Êxodo, 7 à 12), descreve dez pragas ou catástrofes naturais enviadas por Deus para que o rei do Egito pudesse o reconhecer e libertar o seu povo $[\ldots]$.

Com isso, apresentamos o terceiro ponto a ser considerado pelo capelão para a sua abordagem em um contexto catastrófico: A permissão estratégica de Deus na ocorrência de alguns fatos visa possibilitar o seu agir na história do homem. Então, no terceiro momento e certamente o mais delicado de toda a abordagem, o capelão esclarecerá que as ações pecaminosas do homem trazem reflexos a esse mundo e induzem respostas da natureza como consequência dessas ações. $E$, ainda que Deus não se agrade ou não deseje tais consequências ele sem dúvida permite que aconteça tendo como objetivo um plano maior, permitindo que fenômenos naturais o façam conhecido e revelem a sua vontade.

\subsubsection{AS PROVIDÊNCIAS DE DEUS NA HISTÓRIA DA HUMANIDADE PECADORA}

Deus sempre escolhe o momento certo para agir, pois para que o seu propósito e a sua vontade se cumpram os seus atos devem ser compreendidos. Assim que Jó compreendeu que para tudo existe um propósito e uma vontade soberana ele pode declarar: "Bem sei que tudo podes, e nenhum dos teus planos pode ser frustrado." (BÍBLIA, Jó, 42:2). O correto entendimento daquilo que o todo poderoso faz precisa estar relacionado diretamente com aquilo que ele quer fazer. A Bíblia (1993, Jó, 42) diz que Jó obteve a restauração divina quando ouviu a voz de Deus, entendeu o seu plano e orou pelos seus amigos [...]. É fato que, Deus interage com a nossa história e a própria cronologia da história humana mostra que o nascimento do senhor Jesus foi o marco inicial (tendo na cruz a sua consumação), da união de duas realidades (o Deus santo e o homem pecador) então separadas pelo pecado.

Com isso, apresentamos o quarto ponto a ser considerado pelo capelão para a sua abordagem em um contexto catastrófico: A providência restauradora de Deus obedece a um plano gracioso. Então, nesse último momento o capelão cuidará para que o seu assistido tenha entendido o propósito, a vontade e as permissões de Deus 
para a humanidade, levando-o assim a uma condição em que Deus poderá providenciar a sua restauração.

\section{CONSIDERAÇÕES FINAIS}

A Capelania representa a oportunidade legal, estrategicamente estabelecida por Deus, para garantir o direito a assistência religiosa além das quatro paredes da igreja. $E$, no contexto atual em que a ocorrência de desastres naturais tem aumentado consideravelmente, a capelania pós-catástrofe aparece como uma especialização nessa crítica área de atuação.

Considerando que exista entre os seres humanos a falsa sensação de que a causa primária de toda tragédia ambiental esteja em Deus ou pelo menos Deus tenha permitido que acontecesse, foram desenvolvidos quatro pontos para possibilitar ao capelão fazer abordagens estratégicas visando a garantia do perfeito suporte espiritual para esses casos. Esses pontos se baseiam no propósito, na vontade, nas permissões e nas providências de Deus.

O primeiro ponto estabelece o propósito amoroso do criador para a sua criação, uma vez que esse ambiente em que moramos tenha sido cuidadosamente preparado para a nossa perfeita habitação.

O segundo ponto revela a consumação da vontade salvífica do criador, uma vez que a realidade do pecado esteja presente e possua duras consequências.

O terceiro ponto esclarece que as permissões estratégicas de Deus em determinadas ocasiões não revelam a dureza do seu castigo diante de uma humanidade pecadora, mas o poder do seu amor ainda que a humanidade seja pecadora.

O quarto ponto cuida das providências restauradoras de Deus, uma vez que estejam claros o propósito, a vontade e as permissões de Deus, de forma a criar em seu assistido a condição na qual Deus poderá providenciar restauração. 
A história de Jó demonstrou claramente que após a ocorrência das tragédias e as tentativas de assistência religiosa prestadas de forma inadequada, Deus atuou demonstrando que sempre providencia meios para revelar-se e para possibilitar o seu agir transformador. E, através da restauração em todas as áreas da sua vida Jó ainda pode desfrutar durante anos da nova alegria no seu lar [...].

\section{REFERÊNCIAS}

ALVES, Gisleno Gomes de Faria (2017). Manual do capelão: teoria e prática, São Paulo: Hagnos. Disponível em: <https://pt.scribd.com/read/405660345/Manual-docapelao-Teoria-e-pratica>. Acesso em: 23 de mai. 2019

BBC.

Disponível

em:

$<$ https://www.bbc.com/portuguese/noticias/2015/10/151023_nome

S_furacoes_cc>. Acesso em: 23 de mai. 2019

Bíblia. A Bíblia Sagrada: Antigo e Novo Testamento. Tradução em português por João Ferreira de Almeida. Edição revista e atualizada no Brasil. 2o edição. São Paulo: Sociedade Bíblia do Brasil; 1993.

BRASIL, Lei n. 9.982, de 14 jul. de 2000. Prestação de assistência religiosa nas entidades hospitalares públicas e privadas, bem como nos estabelecimentos prisionais civis e militares. Disponível em: < http://www.planalto.gov.br/ccivil_03/Leis/L9982.htm>. Acesso em: 30 de mai. 2019

CASTRO, Antônio Luiz Coimbra. (1998). Glossário de defesa civil: estudo de riscos e medicina de desastres, Brasília: MPO/Departamento de Defesa Civil. Disponível em: $<$ https://pt.scribd.com/document/396881514/RRD-Terminologia-Defesa-Civil>. Acesso em: 23 de mai. 2019

Editora Unesco (2015). Gestão de riscos de desastres para o patrimônio mundial, Brasília, DF: Autor. 
Exame. Disponível em: <https://exame.abril.com.br/noticias-sobre/desastresnaturais/>. Acesso em: 26 de abr. 2019

Fatos Desconhecidos. Disponível em: <https://www.fatosdesconhecidos.com.br/as-5piores-catastrofes-naturais-da-historia/>. Acesso em: 26 de abr. 2019

Nações Unidas Brasil. Disponível em: <https://nacoesunidas.org/atividade-humanacausa-agravamento-de-desastres-naturais-alerta-unesco/>. Acesso em: 29 de abr. 2019

Serviço Nacional de Capelania Pós-desastre. Disponível em: <http://sencapbrasil.blogspot.com/>. Acesso em: 20 de mai. 2019

TOMINAGA, Lídia Keiko, SANTORO, Jair, AMARAL, Rosangela. (2009). Desastres naturais: conhecer para prevenir, São Paulo: Instituto geológico. Disponível em: $<$ https://pt.scribd.com/doc/63758599/DesastresNaturais>. Acesso em: 23 de mai. 2019

Unesco. Disponível em: <http://www.unesco.org/new/pt/rio-20/preparing-fordisaster/>. Acesso em: 29 de abr. 2019

Veja. Disponível em: <https://veja.abril.com.br/mundo/patricia-o-maior-furacaoregistrado-no-mundo-chega-a-costa-do-mexico/>. Acesso em: 23 de mai. 2019

2. Fatos Desconhecidos. Disponível em: <https://www.fatosdesconhecidos.com.br/as5-piores-catastrofes-naturais-da-historia/>. Acesso em: 26/04/2019

3. Exame. Disponível em: <https://exame.abril.om.br/noticias-sobre/desastresnaturais/>. Acesso em: 26/04/2019

4. Unesco. Disponível em: <http://www.unesco.org/new/pt/rio-20/preparing-fordisaster/>. Acesso em: 29/04/2019

5. Nações Unidas Brasil. Disponível em: <https://nacoesunidas.org/atividade-humanacausa-agravamento-de-desastres-naturais-alerta-unesco/>. Acesso em: 29/04/2019 
6. Serviço Nacional de Capelania Pós-desastre. Disponível em: <http://sencapbrasil.blogspot.com/>. Acesso em: 20/05/2019

7. Veja. Disponível em: <https://veja.abril.com.br/mundo/patricia-o-maior-furacaoregistrado-no- mundo-chega-a-costa-do-mexico/>. Acesso em: 23/05/2019

8.

BBC.

Disponível

em:

<https://www.bbc.com/portuguese/noticias/2015/10/151023_nomes_fura- coes_cc>. Acesso em: 23/05/2019

9. Tradução dos nomes para o Latim: Patrícia (Patricius), Pátria (Patriam) e Pai (Patrem).

Enviado: Junho, 2019.

Aprovado: Julho, 2019. 